DOI: https://doi.org/10.24297/jam.v16i0.8175

\title{
Supra Soft b-Compact and Supra Soft b-Lindelöf Spaces
}

\author{
Jamal M. Mustafa \\ Department of Mathematics, Al al-Bayt University, Mafraq, Jordan \\ jjmmrr971@yahoo.com
}

\begin{abstract}
The purpose of this paper is to introduce and study the concepts of supra soft b-compact and supra soft b-Lindelöf spaces. Also we study several of their properties and characterizations in details. Furthermore, the invariance of these kinds of spaces under some types of supra soft mappings and their hereditary properties are also investigated.
\end{abstract}

\section{Introduction}

The concept of soft sets was first introduced by Molodtsov [23] in 1999 as a general mathematical tool for dealing with uncertain objects while modelling the problems with incomplete information in engineering, physics, computer science, economics, social sciences and medical sciences. In [24], Molodtsov applied soft sets successfully in directions such as smoothness of functions, game theory, operations research, Riemann-integration, Perron integration, probability and theory of measurement. Maji et. al [21] applied soft sets in a multicriteria decision making problems. It is based on the notion of knowledge reduction of rough sets. They applied the technique of knowledge reduction to the information table induced by the soft set. In [22], they defined and studied several basic notions of soft set theory. In 2005, Pei and Miao [26] and Chen [5] improved the work of Maji et.al [21-22]. A. Kharal and B. Ahmad [20] defined and discussed the several properties of soft images and soft inverse images of soft sets. They also applied these notions to the problem of medical diagnosis in medical systems. Many researchers have contributed towards the algebraic structure of soft set theory [2-3],[4], [7], [10-20], [25], [28-29]. In 2011, Shabir and Naz [28] initiated the study of soft topological spaces. Also in 2011, S. Hussain and B. Ahmad [9] continued investigating the properties of soft open(closed), soft neighbourhood and soft closure. They also defined and discussed the properties of soft interior, soft exterior and soft boundary. Shabir et. al [28] and D. N. Georgiou et. al [7], defined and studied some soft separation axioms, soft -continuity and soft connectedness in soft spaces using (ordinary) points of a topological space X. Ittanagi [10] introduced the concept of soft bitopological space and studied some types of soft separation axioms for soft bitopological spaces from his point of view. In this paper, we introduce the concepts of supra soft b-compact and supra soft b-Lindelöf spaces. Furthermore, several of their properties and characterizations are studied. Also, the behavior of these kinds of spaces under some types of supra soft mappings has obtained.

\section{Preliminaries}

In this section we will introduce necessary Definitions and Theorems for soft sets.

[Definition 2.1. [23] Let $X$ be an initial universe and $E$ a set of parameters. Let $P(X)$ denote the power set of $X$. A pair $(F, E)$ is called a soft set over $X$, where $F$ is a mapping given by $F: E \rightarrow P(X)$. In other words, a soft set over $X$ is a parameterized family of subsets of the universe $X$. For $e \in E, F(e)$ may be considered as the set of e-approximate elements of the soft set $(F, E)$.

[Definition $2.2[23]$ The complement of a soft set $(F, E)$ is denoted by $(F, E)^{c}$ and is defined by $(F, E)^{c}=\left(F^{c}, E\right)$ where, $F^{c}: E \rightarrow P(X)$ is a mapping given by $F^{c}(e)=X-F(e)$, for all $e \in E$.

Let us call $F^{c}$ to be the soft complement function of $F$. Clearly $\left(F^{c}\right)^{c}$ is the same as $F$ and $\left((F, E)^{c}\right)^{c}=(F, E)$. 
[Definition 2.3 [31] A soft set $(F, E)$ over $X$ is said to be a null soft set, denoted by $\widetilde{\phi}$, if for all $e \in E, F(e)=\phi$. Clearly, $\left(\widetilde{\phi}^{c}\right)^{c}=\widetilde{\phi}$.

[Definition $2.4[31]$ A soft set $(F, E)$ over $X$ is said to be an absolute soft set, denoted by $\widetilde{X}$, if for all $e \in E$, $F(e)=X$. Clearly, $\widetilde{X}^{c}=\widetilde{\phi}$.

[Definition $2.5[22]$ Let $(F, E),(G, E)$ be two soft sets over X. Then,

(1) $(F, E)$ is a soft subset of $(G, E)$, denoted by $(F, E) \widetilde{\subseteq}(G, E)$, if $F(e) \subseteq G(e), \forall e \in E$. In this case, (F, E) is said to be a soft subset of $(G, E)$ and $(G, E)$ is said to be a soft superset of $(F, E)$.

(2) Two soft sets $(F, E)$ and $(G, E)$ over a common universe set $X$ are said to be equal, denoted by $(F, E)=(G, E)$, if $F(e)=G(e), \forall e \in E$.

(3) The union of two soft sets $(F, E)$ and $(G, E)$ over the common universe $X$, denoted by $(F, E) \widetilde{\cup}(G, E)$, is the soft set $(H, E)$, where $H(e)=F(e) \cup G(e)$, for all $e \in E$.

(4) The intersection of two soft sets $(F, E)$ and $(G, E)$ over the common universe $X$, denoted by $(F, E) \widetilde{\cap}(G, E)$, is the soft set $(M, E)$, where $M(e)=F(e) \cap G(e)$, for all $e \in E$.

Definition $2.6[28]$ Let $(F, E)$ be a soft set over $X$ and $x \in X$. We say that $x \in(F, E)$ read as $x$ belongs to the soft set $(F, E)$ whenever $x \in F(e)$ for all $e \in E$.

Note that for any $x \in X, x \notin(F, E)$ if $x \notin F(e)$ for some $e \in E$.

Definition 2.7 [28] Let $\tau$ be a collection of soft sets over a universe $X$ with a fixed set of parameters $E$, then $\tau$ is called a soft topology on $X$ if

(1) $\tilde{\phi}, \tilde{X} \in \tau$.

(2) the union of any number of soft sets in $\tau$ belongs to $\tau$.

(3) the intersection of any two soft sets in $\tau$ belongs to $\tau$.

The triplet $(X, \tau, E)$ is called a soft topological space over $X$.

Definition 2.8 [28] Let $(X, \tau, E)$ be a soft topological space, and $(F, E)$ be a soft set over $X$. If $Y$ is a non empty subset of $X$, then the sub soft set of $(F, E)$ over $Y$ denoted by $\left(F_{Y}, E\right)$, is defined as follows:

$F_{Y}(e)=Y \cap F(e)$ for all $e \in E$.

Definition 2.9 [28] Let $(X, \tau, E)$ be a soft topological space and $Y$ be a non empty subset of $X$. Then, $\tau_{Y}=$ $\left\{\left(F_{Y}, E\right):(F, E) \in \tau\right\}$ is called the soft relative topology on $Y$ and $\left(Y, \tau_{Y}, E\right)$ is called a soft subspace of $(X, \tau, E)$.

Definition 2.10 [20] Let $S S(X)_{E}$ and $S S(Y)_{K}$ be families of soft sets on $X$ and $Y$ respectively. Let $u: X \rightarrow Y$ and $p: E \rightarrow K$ be mappings. We define a soft mapping $f_{p u}: S S(X)_{E} \rightarrow S S(Y)_{K}$ as:

(1) If $(F, E) \in S S(X)_{E}$, then, the image of $(F, E)$ under $f_{p u}$, written as $f_{p u}(F, E)=\left(f_{p u}(F)\right.$, $\left.p(E)\right)$, is a soft set in $S S(Y)_{K}$ such that:

$$
f_{p u}(F, E)(k)=\{\} \cup\left\{u[F(e)]: e \in p^{-1}(k)\right\} \text { if } p^{-1}(k) \neq \phi \phi \quad \text { if } p^{-1}(k)=\phi \text { for all } k \in K .
$$

(2) If $(H, K) \in S S(Y)_{K}$, then the inverse image of $(H, K)$ under $f_{p u}$, written as $f_{p u}^{-1}(H, K)=\left(f_{p u}^{-1}(H), E\right)$, is a soft set in $S S(X)_{E}$ such that:

$$
f_{p u}^{-1}(H, K)(e)=u^{-1}[H(p(e))] \text { for all } e \in E \text {. }
$$




\section{Supra Soft b-Open Sets}

[Definition 3.1 [6] Let $\mu$ be a collection of soft sets over a universe $X$ with a fixed set of parameters $E$. Then $\mu$ is called a supra soft topology on $X$ with a fixed set $E$ if:

(1) $\widetilde{\phi}, \widetilde{X} \in \mu$

(2) The union of any number of soft sets in $\mu$ belongs to $\mu$.

$(X, \mu, E)$ is called supra soft topological space and the elements of $\mu$ are called supra soft open sets. The soft complement of any supra soft open set is called supra soft closed.

[1]Definition 3.2 A collection $\left\{\left(F_{i}, E\right): i \in I\right\}$ of supra soft open sets in a supra soft topological space $(X, \mu, E)$ is called a supra soft open cover of a soft set $(F, E)$ if $(F, E) \widetilde{\widetilde{U}}\left\{\left(F_{i}, E\right): i \in I\right\}$ holds.

[Definition 3.3 A soft subset $(F, E)$ of the space $(X, \mu, E)$ is said to be soft supra combact (resp. soft supra Lindelöf), if for every supra soft open cover $\left\{\left(F_{i}, E\right): i \in I\right\}$ of $(F, E)$ there exists a finite (resp. countable) subset $I_{0}$ of $I$ such that $(F, E) \widetilde{\widetilde{U}}\left\{\left(F_{i}, E\right): i \in I_{0}\right\}$.

The space $(X, \mu, E)$ is said to be soft supra compact (resp. soft supra Lindelöf) if $\widetilde{X}$ is soft supra compact (resp. soft supra Lindelöf) as a soft subset.

Definition 3.4 Let $(X, \mu, E)$ be a supra soft topological space and $Y$ be a non empty subset of $X$. Then, $\mu_{Y}=$ $\left\{\left(F_{Y}, E\right):(F, E) \in \mu\right\}$ is called the supra soft relative topology on $Y$ and $\left(Y, \mu_{Y}, E\right)$ is called a supra soft subspace of $(X, \mu, E)$.

[Definition $3.5[6]$ Let $(X, \mu, E)$ be a supra soft topological space and $(F, E)$ be a soft set over $X$. Then the supra soft interior of $(F, E)$, denoted by $i n t^{s}(F, E)$ is the soft union of all supra soft open subsets of $(F, E)$. Clearly int ${ }^{s}(F, E)$ is the largest supra soft open set over $X$ which contained in $(F, E)$.

[Definition $3.6[6]$ Let $(X, \mu, E)$ be a supra soft topological space and $(F, E)$ be a soft set over $X$. Then the supra soft closure of $(F, E)$, denoted by $c l^{s}(F, E)$ is the soft intersection of all supra soft closed sets containing $(F, E)$. Clearly $c l^{s}(F, E)$ is the smallest supra soft closed set over $X$ which contains $(F, E)$.

Definition 3.7 A soft set $(F, E)$ in a supra soft topological space $X$ is called

(1) supra soft b-open (ssb-open) set if $(F, E) \widetilde{\widetilde{C}} i n t^{s}\left(c l^{s}(F, E)\right) \widetilde{\cup} c l^{s}\left(i n t^{s}(F, E)\right)$.

(2) supra soft b-closed (ssb-closed) set if $(F, E) \supseteq n t^{s}\left(c l^{s}(F, E)\right) \widetilde{n} c l^{s}\left(i n t^{s}(F, E)\right)$.

We denote the family of all ssb-open (resp. ssb-closed) sets in a supra soft topological space $X$ by $\mathrm{SSBO}(\mathrm{X})$ (resp. $\operatorname{SSBC}(\mathrm{X}))$.

Definition 3.8 Let $(X, \mu, E)$ be a supra soft topological space and $(F, E)$ be a soft set over $X$. Then the supra soft b-interior of $(F, E)$, denoted by $\operatorname{int}_{b}^{s}(F, E)$ is the soft union of all supra soft b-open subsets of $(F, E)$. Clearly $\operatorname{int}_{b}^{s}(F, E)$ is the largest supra soft b-open set over $X$ which contained in $(F, E)$.

Definition 3.9 Let $(X, \mu, E)$ be a supra soft topological space and $(F, E)$ be a soft set over $X$. Then the supra soft b-closure of $(F, E)$, denoted by $c l_{b}^{s}(F, E)$ is the soft intersection of all supra soft b-closed sets containing $(F, E)$. Clearly $c l_{b}^{s}(F, E)$ is the smallest supra soft b-closed set over $X$ which contains $(F, E)$.

Definition 3.10 A soft mapping $f_{p u}:(X, \mu, E) \rightarrow(Y, \sigma, K)$ is said to be

(1) supra soft b-continuous (briefly ssb-continuous) if the inverse image of each supra soft open set of $(Y, \sigma, K)$ is 
a supra soft b-open set in $(X, \mu, E)$.

(2) supra soft b-open if the image of each supra soft open set of $(X, \mu, E)$ is supra soft b -open set in $(Y, \sigma, K)$.

(3) supra soft b-irresolute if the inverse image of each supra soft b-open set of $(Y, \sigma, K)$ is a supra soft b-open set in $(X, \mu, E)$.

(4) supra soft $\mathrm{b}^{*}$-open if the image of each supra soft b-open set of $(X, \mu, E)$ is supra soft b-open set in $(Y, \sigma, K)$.

\section{Supra Soft b-Compact and Supra soft b-Lindelöf Spaces}

Definition 4.1 A collection $\left\{\left(F_{i}, E\right): i \in I\right\}$ of supra soft b-open sets in a supra soft topological space $(X, \mu, E)$ is called a supra soft b-open cover of a soft set $(F, E)$ if $(F, E) \widetilde{\subseteq} \widetilde{\cup}\left\{\left(F_{i}, E\right): i \in I\right\}$ holds.

Definition $4.2 \mathrm{~A}$ soft subset $(F, E)$ of the space $(X, \mu, E)$ is said to be supra soft b-combact (resp. supra soft bLindelöf), if for every supra soft b-open cover $\left\{\left(F_{i}, E\right): i \in I\right\}$ of $(F, E)$ there exists a finite (resp. countable) subset $I_{0}$ of $I$ such that $(F, E) \stackrel{\widetilde{\widetilde{U}}}{\cup}\left\{\left(F_{i}, E\right): i \in I_{0}\right\}$.

The space $(X, \mu, E)$ is said to be supra soft b-compact (resp. supra soft b-Lindelöf) if $\widetilde{X}$ is supra soft b-compact (resp. supra soft b-Lindelöf) as a soft subset.

Theorem 4.3. Every supra soft b-compact space is soft supra compact.

Proof Comes from the fact that every supra soft open set is supra soft b-open.

Theorem 4.4. If $X$ is finite (resp. countable), then $(X, \mu, E)$ is supra soft b-compact (resp. supra soft b-Lndelöf) for any supra soft topology $\mu$ on $X$.

Proof Obvious.

Theorem 4.5. Every supra soft b-closed subspace of a supra soft b-compact space is supra soft b-compact.

Proof Let $(F, E)$ be a supra soft b-closed subspace of a supra soft b-compact space $(X, \mu, E)$ and $\left\{\left(F_{i}, E\right): i \in I\right\}$ be a supra soft b-open cover of $(F, E)$. Then, $\left\{\left(F_{i}, E\right): i \in I\right\} \widetilde{\cup}\left(F^{c}, E\right)$ is a supra soft b-open cover of $\widetilde{X}$ and since $\widetilde{X}$ is supra soft b-compact, there exists a finite subcover $\left\{\left(F_{i}, E\right): i \in I_{0}\right\} \widetilde{\cup}\left(F^{c}, E\right)$ for $\widetilde{X}$. Now, [\{(F, E) : $i \in$ $\left.\left.I_{0}\right\} \widetilde{\cup}\left(F^{c}, E\right)\right]-\left(F^{c}, E\right)$ is a finite subcover of $\left\{\left(F_{i}, E\right): i \in I\right\}$ for $(F, E)$. So, $(F, E)$ is supra soft b-compact.

Theorem 4.7 Every supra soft b-closed subspace of a supra soft b-Lindelöf space is supra soft b-Lindelöf.

Proof It is similar to the proof of the above theorem.

Theorem 4.7. In a supra soft topological space $(X, \mu, E)$, if $(F, E)$ is a supra soft b-compact set and $(K, E)$ is a supra soft b-open set contained in $(F, E)$. Then, $(F, E)-(K, E)$ is supra soft b-compact.

Proof Let $\left\{\left(F_{i}, E\right): i \in I\right\}$ be a supra soft b-open cover of $(F, E)-(K, E)$. Then, $(F, E)-(K, E) \widetilde{\widetilde{\cup}}\left\{\left(F_{i}, E\right): i \in I\right\}$. Since $(K, E) \widetilde{\widetilde{\subseteq}}(F, E)$ and $(K, E)$ is supra soft b-open, $(F, E) \widetilde{\widetilde{\cup}}\left\{\left(F_{i}, E\right): i \in I\right\} \widetilde{\cup}(K, E)$. Since (F,E) is supra soft b-compact, there exists a finite subfamily $I_{0}$ of $I$ such that $(F, E) \widetilde{\widetilde{C}} \widetilde{\cup}\left\{\left(F_{i}, E\right): i \in I_{0}\right\} \widetilde{\cup}(K, E)$. Therefore, $(F, E)-(K, E) \widetilde{\subseteq} \widetilde{\cup}\left\{\left(F_{i}, E\right): i \in I_{0}\right\} \widetilde{\cap}\left(K^{c}, E\right) \widetilde{\subseteq} \widetilde{\cup}\left\{\left(F_{i}, E\right): i \in I_{0}\right\}$, and hence $(F, E)-(K, E)$ is supra soft b-compact.

Theorem 4.8. The soft union of two supra soft b-compact (resp. supra soft b-Lindelöf) sets is supra soft b-compact (resp. supra soft b-Lindelöf). 
Proof Let $(F, E)$ and $(H, E)$ be two supra soft b-compact sets. Assume that $\left\{\left(F_{i}, E\right): i \in I\right\}$ is a supra soft b-open cover of $(F, E) \widetilde{\cup}(H, E)$. Then, $\left\{\left(F_{i}, E\right): i \in I\right\}$ is a supra soft b-open cover of $(F, E)$ and $(H, E)$. Since $(F, E)$ and $(H, E)$ are supra soft b-compact, there exist finite subfamilies $I_{0}$ and $I_{1}$ of $I$ such that $(F, E) \widetilde{\widetilde{\subseteq}}\left\{\left(F_{i}, E\right): i \in I_{0}\right\}$ and $(H, E) \widetilde{\subseteq} \widetilde{\cup}\left\{\left(F_{i}, E\right): i \in I_{1}\right\}$. Hence, $(F, E)-(H, E) \widetilde{\subseteq}\left(\widetilde{\cup}\left\{\left(F_{i}, E\right): i \in I_{0}\right\}\right) \widetilde{\cup}\left(\widetilde{\cup}\left\{\left(F_{i}, E\right): i \in I_{1}\right\}\right)$. It follows that, $\left.(F, E)-(H, E) \widetilde{\widetilde{\cup}}\left\{\left(F_{i}, E\right): i \in I_{0} \cup I_{1}\right\}\right)$ Thus, $(F, E)-(H, E)$ is supra soft b-compact.

The proof of the case of supra soft b-Lindelöfness is similar.

Corollary 4.9. The finite (resp. countable) soft union of supra soft b-compact (resp. supra soft b-Lindelöf) sets is supra soft b-compact (resp. supra soft b-Lindelöf).

Theorem 4.10.Let $(F, E)$ be a supra soft b-compact (resp. supra soft b-Lindelöf) subset of a supra soft topological space $(X, \mu, E)$ and $(K, E)$ be a supra soft b-closed subset of $\widetilde{X}$. Then, $(F, E) \widetilde{\cap}(K, E)$ is supra soft b-compact (resp. supra soft b-Lindelof).

Proof We will show the case when $(F, E)$ is supra soft b-compact subset of $\widetilde{X}$, the other case is similar. Suppose that $\left\{\left(F_{i}, E\right): i \in I\right\}$ is a supra soft b-open cover of $(F, E) \widetilde{\cap}(K, E)$. Then, $\left\{\left(F_{i}, E\right): i \in I\right\} \widetilde{\cup}\left(K^{c}, E\right)$ is a supra soft b-open cover of $(F, E)$. But, $(F, E)$ is supra soft b-compact. So, there exists a finite subfamily $I_{0}$ of $I$ such that $(F, E) \widetilde{\widetilde{\subseteq}}\left\{\left(F_{i}, E\right): i \in I_{0}\right\} \widetilde{\cup}\left(K^{c}, E\right)$. Hence, $(F, E) \widetilde{\cap}(K, E) \widetilde{\subseteq} \widetilde{\cup}\left\{\left(F_{i}, E\right): i \in I_{0}\right\} \widetilde{\cap}(K, E) \widetilde{\widetilde{U}}\left\{\left(F_{i}, E\right): i \in I_{0}\right\}$. Therefore, $(F, E) \widetilde{\cap}(K, E)$ is supra soft b-compact.

Theorem 4.11. Every supra soft subspace of a supra soft topological space $(X, \mu, E)$ is supra soft b-compact if and only if every supra soft b-open subspace of $\widetilde{X}$ is supra soft b-compact.

Proof For the necessity, it is obvious. Conversely, let $\left(Y, \mu_{Y}, E\right)$ be a supra soft b-open subspace of supra soft topological space $(X, \mu, E)$ and $\left\{\left(F_{i}, E\right): i \in I\right\}$ be a supra soft b-open cover of $\widetilde{Y}$. Assume that $(F, E)=\widetilde{\cup}\left\{\left(F_{i}, E\right): i \in I_{0}\right\}$. Then, $(F, E)$ is supra soft b-open subspace of $\widetilde{X}$. By hypothesis, $(F, E)$ is supra soft b-compact. So, there exists a finite subfamily $I_{0}$ of $I$ such that $(F, E) \widetilde{\subseteq} \widetilde{\cup}\left\{\left(F_{i}, E\right): i \in I_{0}\right\}$. Hence $(Y, E) \widetilde{\subseteq}(F, E) \widetilde{\subseteq} \widetilde{\cup}\left\{\left(F_{i}, E\right): i \in I_{0}\right\}$. Therefore, $\left(Y, \mu_{Y}, E\right)$ is supra soft b-compact.

Theorem 4.12. Every supra soft subspace of a supra soft topological space $(X, \mu, E)$ is supra soft b-Lindelöf if and only if every supra soft b-open subspace of $\widetilde{X}$ is supra soft b-Lindelof.

Proof It similar to the proof of the above theorem.

[Definition 4.13.[31] A family $\Psi$ of soft sets has the soft finite intersection property if the intersection of the members of each finite subfamily of $\Psi$ is not null soft set.

Definition 4.14.A supra soft topological space $(X, \mu, E)$ is supra soft b-compact if and only if for every family $\left\{\left(F_{i}, E\right)\right.$ : $i \in I\}$ of supra soft b-closed sets of $(X, \mu, E)$ having the finite intersection property,we have $\widetilde{\cap}\left\{\left(F_{i}, E\right): i \in I\right\} \neq \widetilde{\phi}$.

Proof Let $\left\{\left(F_{i}, E\right): i \in I\right\}$ be a family of supra soft b-closed sets with the finite intersection property. Assume that $\widetilde{\cap}\left\{\left(F_{i}, E\right): i \in I\right\}=\widetilde{\phi}$. Then $\widetilde{\cup}\left\{\left(F_{i}, E\right)^{c}: i \in I\right\}=\widetilde{X}$. Since $\left\{\left(F_{i}, E\right)^{c}: i \in I\right\}$ is a collection of supra soft b-open sets covering $(X, \mu, E)$, and $(X, \mu, E)$ is supra soft b-compact, it follows that there exists a finite subset $I_{0}$ of $I$ such that $\widetilde{\cup}\left\{\left(F_{i}, E\right)^{c}: i \in I_{0}\right\}=\widetilde{X}$. Then $\widetilde{\cap}\left\{\left(F_{i}, E\right): i \in I_{0}\right\}=\widetilde{\phi}$, which gives a contradictions. Therefore $\widetilde{\cap}\left\{\left(F_{i}, E\right): i \in I\right\} \neq \widetilde{\phi}$.

Conversely, $\left\{\left(F_{i}, E\right): i \in I\right\}$ be a family of supra soft b-open sets covering $(X, \mu, E)$. Suppose that for every finite subset $I_{0}$ of $I$, we have $\widetilde{\cup}\left\{\left(F_{i}, E\right): i \in I_{0}\right\} \neq \widetilde{X}$. Then $\widetilde{\cap}\left\{\left(F_{i}, E\right)^{c}: i \in I_{0}\right\} \neq \widetilde{\phi}$. Hence $\left\{\left(F_{i}, E\right)^{c}: i \in I\right\}$ satisfy the finite intersection property. Then by definition we have $\widetilde{\cap}\left\{\left(F_{i}, E\right)^{c}: i \in I\right\} \neq \widetilde{\phi}$ which implies $\widetilde{\cup}\left\{\left(F_{i}, E\right): i \in I\right\} \neq \widetilde{X}$ and this contradicts that $\left\{\left(F_{i}, E\right): i \in I\right\}$ is a supra soft b-cover of $(X, \mu, E)$. Thus $(X, \mu, E)$ is supra soft b-compact space. 
Definition 4.15. Let $f_{p u}:(X, \mu, E) \rightarrow(Y, \sigma, K)$ be a supra soft b-continuous function. If $(X, \mu, E)$ is supra soft b-compact space, then the image of $(X, \mu, E)$ under $f$ is supra soft compact.

Proof Let $f_{p u}:(X, \mu, E) \rightarrow(Y, \sigma, K)$ be a supra soft b-continuous function from a supra soft b-compact space $(X, \mu, E)$ onto $(Y, \sigma, K)$. Take a supra soft open cover $\left\{\left(G_{i}, K\right): i \in I\right\}$ of $(Y, \sigma, K)$. For $f_{p u}$ is supra soft bcontinuous, $\left\{f_{p u}^{-1}\left(G_{i}, K\right): i \in I\right\}$ is a supra soft b-open cover of $(X, \mu, E)$, but $(X, \mu, E)$ is supra soft b-compact, then there exists a finite subset $I_{0}$ of $I$ such that $\left\{f_{p u}^{-1}\left(G_{i}, K\right): i \in I_{0}\right\}$ forms a supra soft b-open cover of $(X, \mu, E)$. Thus, $\left\{\left(G_{i}, K\right): i \in I_{0}\right\}$ forms a finite supra soft open cover of $(Y, \sigma, K)$.

Definition 4.16 A supra soft topological space $(X, \mu, E)$ is called supra soft b-space if every supra soft b-open set of $(X, \mu, E)$ is supra soft open set in $(X, \mu, E)$.

Definition 4.17.If $(X, \mu, E)$ is a supra soft b-compact space and supra soft b-space, then $(X, \mu, E)$ is supra soft compact space.

Proof Let $\left\{\left(F_{i}, E\right): i \in I\right\}$ be a supra soft open cover of $(X, \mu, E)$. Since any supra soft open set is supra soft b-open set, $\left\{\left(F_{i}, E\right): i \in I\right\}$ is a supra soft b-open cover of $(X, \mu, E)$. Since $(X, \mu, E)$ is supra soft b-compact space and supra soft b-space, there exists a finite subset $I_{0}$ of $I$ such that $\widetilde{X} \widetilde{\subseteq} \widetilde{\cup}\left\{\left(F_{i}, E\right): i \in I_{0}\right\}$. Hence $(X, \mu, E)$ is supra soft compact space.

Definition 4.18. If $f_{p u}:(X, \mu, E) \rightarrow(Y, \sigma, K)$ is a supra soft b-continuous function and $(X, \mu, E)$ is a supra soft b-space, then $f_{p u}$ is supra soft continuous.

Proof Let $(F, E)$ be a supra soft open set of $(Y, \sigma, K)$. For $f_{p u}$ is supra soft b-continuous function, $f_{p u}^{-1}((F, E))$ is a supra soft b-open set of $(X, \mu, E)$ and for $(X, \mu, E)$ is supra soft b-space, $f_{p u}^{-1}((F, E))$ forms a supra soft open set of $(X, \mu, E)$. Hence $f_{p u}$ is a supra soft continuous function.

Definition 4.19 Let $f_{p u}:(X, \mu, E) \rightarrow(Y, \sigma, K)$ be a supra soft b-continuous function, supra soft b-open and injective mapping. If a soft subset $(F, E)$ of $(Y, \sigma, K)$ is supra soft b-compact in $Y$, then $f_{p u}^{-1}((F, E))$ is supra soft b-compact in $(X, \mu, E)$.

Proof Let $\left\{\left(F_{i}, E\right): i \in I\right\}$ be a supra soft b-open cover of $f_{p u}^{-1}((F, E))$ in $(X, \mu, E)$. Then $f_{p u}^{-1}((F, E)) \widetilde{\subseteq} \widetilde{\cup}\left\{\left(F_{i}, E\right): i \in\right.$ $I\}$ and hence $(F, E) \widetilde{\subseteq} \widetilde{\cup}\left\{f_{p u}\left(F_{i}, E\right): i \in I\right\}$. Since $(F, E)$ is supra soft b-compact in $(Y, \sigma, K)$, there is a finite subset $I_{0}$ of $I$ such that $(F, E) \widetilde{\widetilde{\cup}}\left\{f_{p u}\left(F_{i}, E\right): i \in I_{0}\right\}$. So $f_{p u}^{-1}((F, E)) \widetilde{\subseteq} f_{p u}^{-1}\left(\widetilde{\cup}\left\{f_{p u}\left(F_{i}, E\right): i \in I_{0}\right\}\right)=\widetilde{\subseteq} \widetilde{\cup}\left\{\left(F_{i}, E\right): i \in I_{0}\right\}$. Then $f_{p u}^{-1}((F, E))$ is supra soft b-compact in $(X, \mu, E)$.

Definition 4.20 If a function $f_{p u}:(X, \mu, E) \rightarrow(Y, \sigma, K)$ is supra soft b-irresolute and $(F, E)$ is supra soft b-compact relative to $(X, \mu, E)$, then the image $f_{p u}((F, E))$ is supra soft b-compact in $(Y, \sigma, K)$.

Proof Let $\left\{\left(F_{i}, E\right): i \in I\right\}$ be a supra soft b-open cover of $f_{p u}((F, E))$ in $(Y, \sigma, K)$. For $f_{p u}$ is supra soft birresolute function, $\left\{f_{p u}^{-1}\left(F_{i}, E\right): i \in I\right\}$ is supra soft b-open cover of $(F, E)$ in $(X, \mu, E)$. For $(F, E)$ is supra soft b-compact relative to $(X, \mu, E)$, there is a finite subset $I_{0}$ of $I$ such that $(F, E) \widetilde{\simeq} \widetilde{\cup}\left\{f_{p u}^{-1}\left(F_{i}, E\right): i \in I_{0}\right\}$. Thus $f_{p u}((F, E)) \widetilde{\subseteq} f_{p u}\left(\widetilde{\cup}\left\{f_{p u}^{-1}\left(F_{i}, E\right): i \in I_{0}\right\}\right)$, and hence $\left.f_{p u}((F, E)) \widetilde{\subseteq} \widetilde{\cup}\left\{\left(F_{i}, E\right): i \in I_{0}\right\}\right)$. Therefore $f_{p u}((F, E))$ is supra soft b-compact in $(Y, \sigma, K)$.

Definition 4.21 If a function $f_{p u}:(X, \mu, E) \rightarrow(Y, \sigma, K)$ is supra soft $\mathrm{b}^{*}$-open bijective mapping and $(Y, \sigma, K)$ is soft b-compact space, then $(X, \mu, E)$ is soft b-compact space.

Proof Let $\left\{\left(F_{i}, E\right): i \in I\right\}$ be a collection of supra soft b-open covering of $(X, \mu, E)$. Then $\left\{f_{p u}\left(F_{i}, E\right): i \in I\right\}$ is a supra soft b-open cover of $(Y, \sigma, K)$. Since $(Y, \sigma, K)$ is a supra soft b-compact space, there exists a finite subset $I_{0}$ of $I$ such that $\left\{f_{p u}\left(F_{i}, E\right): i \in I_{0}\right\}$ covers $(Y, \sigma, K)$. Also since $f_{p u}$ is bijective we have $X=f_{p u}^{-1}(Y)=f_{p u}^{-1}\left(\widetilde{\cup}\left\{f_{p u}\left(F_{i}, E\right)\right.\right.$ : $\left.\left.i \in I_{0}\right\}\right)=\widetilde{\cup}\left\{\left(F_{i}, E\right): i \in I_{0}\right\}$. Thus $(X, \mu, E)$ is supra soft b-compact space. 


\section{References}

[1] A. M. Abd El-latif: On Soft Supra Compactness in Supra Soft Topological Spaces, Tblisi Mathematical Journal 11(1) (2018) $169-178$.

[2] U. Acar, F. Koyuncu, B. Tanay: Soft sets and soft rings, Computers and Mathematics with Applications 59 (2010) 3458-3463.

[3] H. Aktas, N. Cagman: Soft sets and soft groups, Information Sciences 1(77) (2007) 2726-2735.

[4] N. Cagman, S. Karatas, S. Enginoglu: Soft Topology, Computers and Mathematics with Applications 62 (2011) 351-358.

[5] D. Chen: The parametrization reduction of soft sets and its applications, Computers and Mathematics with Applications 49 (2005) 757-763.

[6] S. A. El-Sheikh and A. M. Abd El-Latif: Decompositions of some types of supra soft sets and soft continuity, International Journal of Mathematics Trends and Technology 9(1) (2014) 37-56.

[7] D. N. Georgiou, A. C. Megaritis, V. I. Petropoulos: On Soft Topological Spaces, Applied Mathematics and Information Sciences 7(2) (2013) 1889-1901.

[8] M. B. Gorzalzany: A method of inference in approximate reasoning based on interval-valued fuzzy sets, Fuzzy Sets and Systems 21 (1987) 1-17.

[9] S. Hussain, B. Ahmad : Some Properties of Soft Topological Spaces, Computers and Mathematics with Applications 62 (2011) 4058-4067.

[10] B. M. Ittanagi: Soft Bitopological Spaces, International Journal of Computer Applications 107(7) (2014) 1-4.

[11] Y. B. Jun: Soft BCK/BCI-algebras, Computers and Mathematics with Applications 56 (2008) 1408-1413.

[12] Y. B. Jun, C. H. Park: Applications of soft sets in ideal theory of BCK/BCI-algebras, Information Sciences 178 (2008) 2466-2475.

[13] Y. B. Jun, C. H. Park: Applications of soft sets in Hilbert algebras, Iranian Journal Fuzzy Systems 6(2) (2009) 55-86.

[14] Y. B. Jun, H. S. Kim, J. Neggers: Pseudo d-algebras, Information Sciences 179 (2009) 1751-1759.

[15] Y. B. Jun, K. J. Lee, A. Khan: Soft ordered semigroups, Mathematical Logic Quarterly 56(1) (2010) 42-50.

[16] Y. B. Jun, K. J. Lee, C. H. Park: Soft set theory applied to commutative ideals, in BCKalgebras, Journal of Applied Mathematics Informatics 26(3-4) (2008) 707-720.

[17] Y. B. Jun, K. J. Lee, C. H. Park: Soft set theory applied to ideals in d-algebras, Computers and Mathematics with Applications 57 (2009) 367-378.

[18] Y. B. Jun, K. J. Lee, C. H. Park: Fuzzy soft set theory applied to BCK/BCI-algebras , Computers and Mathematics with Applications 59 (2010) 3180-3192.

[19] Y. B. Jun, C. H. Park: Applications of soft sets in ideal theory of BCK/BCI-Algebras, Inform. Sci. 178 (2008) 2466-2475.

[20] A. Kharral , B. Ahmad : Mappings on soft classes, New Mathematics and Natural Computations, 7(3)(2011), $471-481$.

[21] P. K. Maji, R. Biswas, R. Roy: An application of soft sets in a decision making problem, Computers and Mathematics with Applications 44 (2002) 1077-1083.

[22] P. K. Maji R. Biswas, R. Roy: Soft set theory, Computers and Mathematics with Applications 45 (2003) 555-562.

[23] D. Molodtsov: Soft set theory - first results, Computers and Mathematics with Applications 37 (1999)19-31. 
[24] D. Molodtsov, V. Y. Leonov, D. V. Kovkov: Soft sets technique and its application, Nechetkie Sistemy i Myagkie Vychisleniya 1(1) (2006) 8-39.

[25] Z. Pawlak: Rough sets, Int. J. Comput. Sci. 11 (1982) 341-356.

[26] D. Pie, D. Miao: From soft sets to information systems, Granular Computing, 2005 IEEE Inter. Conf. 2 , $617-621$.

[27] C. H. Park, Y. B. Jun, M. A. Ozturk: Soft WS-algebras, Communications of the Korean Mathematical Society $23(3)$ (2008) 313-324.

[28] M. Shabir, M. Naz: On Soft Topological Spaces, Computers and Mathematics with Applications 61 (2011) 17861799.

[29] Q. M. Sun, Z. L. Zhang, J. Liu: Soft sets and soft modules, Proceedings of Rough Sets and Knowledge Technology, Third International Conference, RSKT 2008, 17-19 May, Chengdu, China, pp. 403-409, 2008.

[30] L. A. Zadeh: Fuzzy sets, Information and Control 8 (1965) 338-353.

[31] I. Zorlutana, N. Akdag, W. K. Min, S. Atmaca: Remarks on Soft Topological Spaces, Annals of Fuzzy Mathematics and Informatics 3(2) (2012) 171-185 